This item was submitted to Loughborough's Research Repository by the author.

Items in Figshare are protected by copyright, with all rights reserved, unless otherwise indicated.

\title{
Suspension polymerization processes
}

PLEASE CITE THE PUBLISHED VERSION

http://dx.doi.org/10.1002/ceat.201000210

PUBLISHER

(c) Wiley-VCH Verlag

VERSION

SMUR (Submitted Manuscript Under Review)

LICENCE

CC BY-NC-ND 4.0

REPOSITORY RECORD

Brooks, Brian W.. 2010. "Suspension Polymerization Processes". figshare. https://hdl.handle.net/2134/7621. 
This item was submitted to Loughborough's Institutional Repository (https://dspace.lboro.ac.uk/) by the author and is made available under the following Creative Commons Licence conditions.

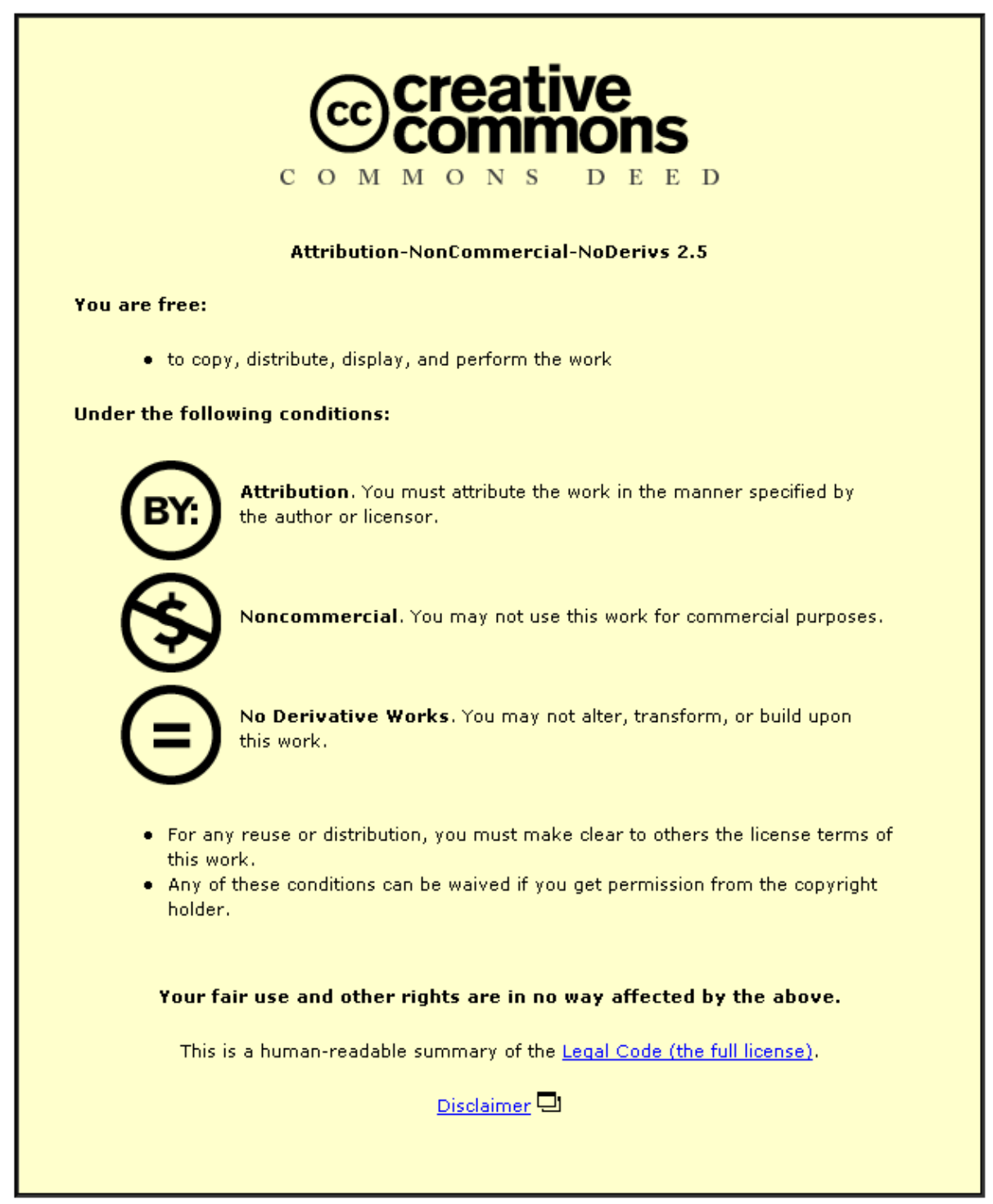

For the full text of this licence, please go to: http://creativecommons.org/licenses/by-nc-nd/2.5/ 


\title{
Suspension polymerization processes
}

\author{
Brian W. Brooks
}

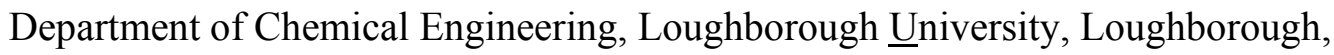
Leicestershire, LE 11 3TU, UK.

\begin{abstract}
Industrial suspension polymerization usually proceeds via a free-radical mechanism to produce polymer beads. The size distribution of the polymer beads is often similar to that of the polymerizing drops in the reactor. That distribution is determined by the operating mechanisms of drop breakage and of drop coalescence. Consequently, the value of the Reynolds Number is significant and a potential change in flow regime must be considered in reactor scale-up. The choice of suspending agent, which can be a watermiscible polymer or a finely divided particulate solid, can affect both the drop size and the properties of the final product. High monomer conversions are attainable but reaction kinetics can be affected by increases in drop viscosity during the polymerization. Drop mixing, which sometimes takes place, can be slow so that non-uniformity occurs in the final product. With copolymerization, complications can arise if the initiator, or one of the monomers, is partially soluble in the continuous phase. Adverse environmental impact of suspension polymerization can be avoided by cleaning and/or recycling of the continuous phase when it leaves the reactor.
\end{abstract}

Keywords: suspension polymerization, suspending agent, flow, viscosity, mixing, reactor scale-up

\section{Introduction}

Suspension polymerization is used for the commercial manufacture of many important polymers including poly(vinyl chloride), poly(methyl methacrylate), expandable polystyrene, styrene-acrylonitrile copolymers and a variety of ion exchange resins. In suspension polymerization, drops of a monomer-containing phase are dispersed in a continuous liquid phase and polymer is produced inside the drops. In many cases, the monomer contains no diluent and the chemical reactions that occur inside the drops are very similar to those that are found in bulk polymerization. In most suspensions, polymer is formed via a chain reaction mechanism that includes the following steps

Initiation:

$$
\begin{gathered}
\mathrm{I} \rightarrow 2 \mathrm{~A}^{*} \\
\mathrm{~A}^{*}+\mathrm{M} \rightarrow \mathrm{AM}^{*}
\end{gathered}
$$

Propagation:

$$
\mathrm{AM}_{\mathrm{n}} *+\mathrm{M} \rightarrow \mathrm{AM}_{\mathrm{n}+1} *
$$

Termination:

$$
\begin{aligned}
& \mathrm{AM}_{\mathrm{n}}^{*}+\mathrm{AM}_{\mathrm{m}}{ }^{*} \rightarrow \mathrm{AM}_{\mathrm{n}+\mathrm{m}} \mathrm{A} \\
& \mathrm{AM}_{\mathrm{n}}{ }^{*}+\mathrm{AM}_{\mathrm{m}} * \rightarrow \mathrm{AM}_{\mathrm{n}}+\mathrm{AM}_{\mathrm{m}}
\end{aligned}
$$

Transfer:

$$
\mathrm{AM}_{\mathrm{n}} *+\mathrm{T} \rightarrow \mathrm{AM}_{\mathrm{n}}+\mathrm{T}^{*}
$$

Here, $\mathrm{M}$ is the monomer and $\mathrm{A}^{*}$ could be an anion, a cation or a free radical. In most industrial processes $M$ is a vinyl compound and a free-radical chain mechanism is used. Then, the growing polymer chains, $\mathrm{AM}_{\mathrm{n}}{ }^{*}$, are written as $\mathrm{AM}_{\mathrm{n}}{ }^{*}$. That species has a short life-time (usually $<<1 \mathrm{sec}$ ) and completed polymer molecules are formed throughout the 
process. The generation of radicals, $\mathbf{A}^{\bullet}$, is usually induced by thermal decomposition of an organic initiator, I, that is soluble in the monomer. Organic peroxides are often used as initiators. T represents any species that reacts as a chain transfer agent. $T$ can be monomer, polymer, a solvent or a species that is added specifically to function as a chain transfer agent. If $\mathrm{T}^{*}$ is sufficiently active it can behave as $\mathrm{A}^{*}$ and initiate a new polymer chain. In some cases, such as the polymerization of vinyl chloride, chain transfer to monomer is significant and it has a major effect on the average molecular weight of the polymer. Suspension polymerization has been reviewed previously by Yuan et al. [1], Vivaldo-Lima et al. [2], and Arshady [3].

Although the polymerization chemistry which occurs in the dispersed phase may be similar to that which occurs in the equivalent bulk process it will not be identical unless the monomers and initiator are completely insoluble in the continuous phase and the drop stabilizers (that are usually present) do not participate in the radical reactions. Those conditions are not always satisfied So that complications, which are discussed below, can arise.

In most industrial suspension polymerization agitated batch (or semi-batch) reactors are used and the continuous phase is aqueous. That is advantageous because the process is often exothermic and good heat transfer from the reactor is required. The ratio of surface area to volume is relatively high for small drops so that the rate of heat transfer to the aqueous phase is high. Although drop viscosity may increase substantially, the overall viscosity of the suspension is usually much lower than that which is encountered in the equivalent bulk polymerization. Consequently, agitation of the reactor contents is possible and heat transfer via the aqueous phase to the reactor wall is good. Also, high conversions of monomer to polymer can be achieved inside the drops whereas, in bulk polymerization, increasing viscosity of the polymer-monomer solution often limits the extent of monomer conversion.

Bulk copolymerization may become difficult to control if cross-linking or copolymer precipitation occurs; then, a suspension process may then be the only feasible way in which the copolymerization can be carried out [4].

Suspension polymerization is particularly useful when the final polymer is required to be in the form of small "beads" (which often have the same size distribution as the drops from which they are formed). However, product contamination can be a problem if the drop stabilizers cannot be removed. Suspension polymerization usually requires larger reactor volumes than bulk processes because the vessels are usually half full with water.

The attainment of high monomer conversion can affect the reaction kinetics. From the reaction scheme shown above, it can be shown [5] that the rate of homogeneous polymerization is given by the expression

$$
R_{p}=k_{p} C_{M}\left(\frac{2 f k_{d} C_{I}}{k_{t}}\right)^{1 / 2}
$$

where $C_{I}$ is the concentration of the initiator and $C_{M}$ is the monomer concentration. Here, $k_{p}$ is the propagation rate coefficient, $k_{d}$ is the initiator decomposition rate coefficient and $f$ is an efficiency factor. In equation (1), the overall chain termination rate coefficient, $k_{t}$, is derived from the rate coefficients of the two chain termination steps that are shown in 
the above reaction scheme. At high polymer concentrations, chain termination is often diffusion-controlled and the value of $k_{t}$ diminishes substantially. Radical diffusion can depend on solution viscosity, polymer volume fraction and polymer molecular weight. The latter three entities are interrelated in complicated ways [6] but the effects of viscosity on polymerization rate can be distinguished from the effects of polymer volume fraction [7]. The value of $f$ may depend on polymer content [8] and the value of $k_{p}$ may also decrease [9]. From equation (1), it can be seen that the reduction in $k_{t}$ leads to an increase in the polymerization rate, a phenomenon often described as a "gel effect".

\section{Suspending agents}

In the absence of a drop stabilizer, the suspension would be unstable and the monomer/polymer drops would coalesce and become large. That is undesirable because, often, it is necessary to obtain a specific size distribution for the final polymer particles. Therefore, control of drop size, and of drop stability, during polymerization becomes important. Drop stability depends largely on the nature of the drop stabilizer (or suspending agent). Adsorption of stabilizer molecules on the outer drop surface can reduce the interfacial tension and, hence, lower the energy required for drop formation. However, drop stability against coalescence depends largely on the ability of the stabilizer to form a protective film at the interface. Increasing the stabilizer concentration continues to improve the elastic properties of the drops until a "critical surface coverage" is attained; further increases then have a very little effect on the drop stability $[10,11]$

Water-miscible polymers, both naturally-occurring and synthetic, are often used as drop stabilizers. Initially, these materials are dispersed in the continuous phase; subsequent migration to the surfaces of newly-created monomer drops may be rapid but the development of drop stability may be slow because rearrangement of stabilizer molecules on the drop surface is necessary [12]. When partially hydrolyzed polyvinyl acetate (PVA) is used as a stabilizer its behavior depends on the extent to which the acetate groups are hydrolyzed [13]. Good drop stabilization can be achieved in aqueous media when the degree of hydrolysis $(\mathrm{DH})$ is between $70 \%$ and $80 \%$; then, drops can retain their integrity even when agitation levels are reduced [14]. PVAs with a DH less than $60 \%$ are poor drop stabilizers in aqueous media but they can affect polymer morphology inside the (non-aqueous) drops. That is important in the suspension polymerization of vinyl chloride (VC). In that case, small particles of poly(vinyl chloride) (PVC) precipitate inside the monomer drops because PCV and VC are almost immiscible. Therefore, a mixture of two stabilizers is often used; a "primary stabilizer" which protects the drops from coalescence and a "secondary stabilizer" which effects the behavior of the PVC particles inside the drops and increases polymer porosity [15]. The addition of a secondary stabilizer can also effect the particle size distribution of the polymer particles [16]. PVC porosity can also be increased by using non-ionic surfactants as secondary stabilizers [17]. PVA can become grafted onto polymer that is formed inside the drops so that a "skin" forms on the final particle surface $[18,19]$. Formation of that skin, which is difficult to remove, can affect the final polymer properties. With some monomers, product contamination can be avoided by using alternative suspending agents such as salts of polymethacrylic acid which are not grafted on the particle surface and can be removed from the final polymer product with an aqueous wash $[20,21]$. If the initiator in suspension polymerization is 
slightly soluble in water then simultaneous emulsion polymerization may occur when free stabilizer remains in the continuous phase [22].

\subsection{Particulate drop stabilizers}

Although organic substances are commonly used as drop stabilizers, finely divided particulate inorganic solids can be used to stabilize monomer drops in aqueous suspension via the Pickering effect [23]. An important example is the use of calcium phosphate in the manufacture of expandable polystyrene beads via suspension polymerization [24]. In that case, a blowing agent (often a volatile hydrocarbon) is incorporated in the polymer beads. The blowing agent vaporises, when the beads are subsequently heated, so that the beads expand and fuse to form a foam. With some particulate stabilisers, small amounts of surfactants may be necessary and the effect of electrolytes can also be important [25, 26]. Inorganic stabilizers, such as metal hydroxides, can sometimes be removed from the final polymer particles (by using dilute acids) [24] so that low levels of product contamination are achieved.

The value of the contact angle between the drops and the inorganic solid may determine whether an inorganic solid will act as a stabilizer or as a de-stabilizer in suspension polymerization [27]. Solids that provide a relatively large contact angle (such as aluminium hydroxide) would be stabilizers in aqueous media. In contrast, those which have a relatively small contact angle (such as carbon black) would tend to be destabilizers. However, contact angles with powdered solids are difficult to measure and values may vary with conditions [26]. Mechanisms of drop stabilization by inorganic solids are still a matter for debate [25, 28]. Hydrophobic silica nano-particles have been used to stabilise suspensions of aqueous monomer drops (n-isopropylacrylamide) in nhexane [29]; subsequent suspension polymerisation led to the formation of particles with a core-shell structure [29]. Other types of dispersed solids, such as polystyrene latex particles, can also be used to stabilize drops in liquid-liquid systems [30, 31, 32].

\section{Suspension co-polymerization}

Functional groups can be introduced via co-polymerization with appropriate monomers [33] but control and prediction of co-polymer compositions in suspension polymerization can be difficult if one, or more, of the monomers is partially soluble in the continuous phase. Then, the actual monomer concentrations in the drops may be unknown so that idealized relationships for predicting co-polymer compositions, which apply to homogeneous systems, are of little use unless appropriate partition coefficients for the two phases are available. Apparent reactivity ratios, obtained directly from suspension polymerization experiments will be different from those expected for the equivalent bulk processes if some monomer migrates to the continuous phase [34], [35]. In some cases, when the continuous phase is aqueous, models that allow for water solubility of monomers have been developed [4], [36], [37].

\section{Drop formation and stability}

Control of drop size distribution in suspension polymerisation can be important. In many cases, the average drop diameters (and final average particles sizes) lie between 10 and $100 \mu \mathrm{m}$ but larger diameters might be produced if the polymer particles are to be used directly as beads [24]. 
The physical conditions in a suspension polymerization reactor affect the drop size distribution significantly. Drop breakage in agitated suspensions can be caused either by frictional forces (via viscous shear) or by inertial forces (via turbulence) [38]. In industrial suspension polymerisation, the volume fraction of dispersed phase is usually high and drop break-up is accompanied by drop coalescence. Thus, the average drop size and the drop size distribution are both influenced by drop breakage and by drop coalescence.

\subsection{Suspensions with turbulent flow}

In large vessels, agitated aqueous suspensions are often turbulent. If turbulence is isotropic and the diameter exceeds the Kolmogorov length then turbulent pressure fluctuations will cause drop breakage [4], [11]. By applying some simplifying assumptions, the average drop size is sometimes given by equation (2)

$\frac{d_{32}}{D}=a(1+b \phi) W e^{-0.6}$

Here, $d_{32}$ is the Sauter-mean drop diameter, $\phi$ is the volume fraction of the dispersed phase, $D$ is the impeller diameter and $a$ and $b$ are constants [39]. The Weber number, $W e$, is given by

$W e=\frac{\rho_{m} N^{2} D^{3}}{\sigma}$

where $N$ is the stirrer speed, $\rho_{m}$ is the dispersion density and $\sigma$ is the interfacial tension.

Equation (2) reflects a balance between inertial forces and interfacial forces but, even when drops are formed via turbulence, application of equation (2) is limited to suspensions in which the dispersed phase has a low viscosity and the drop concentration is low (so that drop coalescence is not significant). Wang and Calabrese [40] showed that, even when turbulence is important, drop break-up can be opposed by both interfacial forces and viscous forces and that the influence of interfacial tension on drop breakage decreases as the dispersed-phase viscosity increases. Drop sizes can take some time to be established and, if polymerisation occurs during that time, the drop viscosity may increase, consequently rates of drop break-up and coalescence will be reduced [41]. Therefore, drop breakage can be a complex process [42] and the polymer particles can have a broad size distribution. In the suspension polymerisation of methyl methacrylate drop viscosity increases significantly and four separate stages have been identified in the drop formation process [43]. In the suspension polymerization of styrene, Konno et al. [44] found that drop coalescence was important and that the Sauter mean diameter increased as the polymer viscosity increased. They also concluded that the stabilizer does not effectively prevent the coalescence of drops with diameters that are larger than those predicted from Weber Number correlations.

The drop coalescence rate can be related to the drop collision frequency and to the coalescence efficiency [45], [46]. Coalescence may occur if drops adhere for sufficient time to allow them to deform, and to permit drainage of the continuous phase that is trapped between them [47]. By taking account of these events, expressions can be obtained for the coalescence efficiency [48]. 


\subsection{Drop breakage via viscous shear}

If the viscosity of the continuous phase is not low enough to obtain high values for the Reynolds Number then drop breakage via turbulence may not be possible. But drop breakage may then be caused by viscous shear [49], [50]. Jegat et al. [51] found that, in the suspension co-polymerization of styrene and divinylbenzene, the maximum diameter of the co-polymer beads ceased to be determined by inertial drop break-up when the viscosity of the continuous phase was high enough to give a Taylor Number less than 400. Then, the maximum diameters corresponded to predictions from a viscous shear break-up model.

Here, the Taylor Number is given by

$T a=\frac{N D \pi e}{v_{c}}\left(\frac{2 e}{D}\right)^{0.5}$

where, $N$ is the stirring speed, $D$ is the impeller blade diameter, $e$ is the distance between the impeller blade and the reactor wall and $v_{c}$ is the kinematic viscosity.

In the suspension polymerisation of methyl methacrylate, using sodium polymethacrylate as a suspending agent [52], increases in the sodium polymethacrylate concentration produced significant increases in the continuous phase viscosity. Then, the maximum drop diameter was no longer compatible with the Kolmogorov theory but the drop diameter became a function of the Taylor Number, indicating that drop breakage was induced by viscous shear. In that case, the interfacial tension was almost independent of the suspending agent concentration and the continuous phase was non-Newtonian (viscosity decreased with increasing agitation rate). Similar results were obtained when ammonium polymethacrylate was used as a suspending agent [53], [54]. The viscosity of the continuous phase also depended on the $p H$. The initial value of the $p H$ exerted a significant influence on the drop sizes and particle sizes, without affecting the interfacial tension. With both stabilisers, monomer hydrolysis led to diminution of $\mathrm{pH}$ during the polymerization; but the continuous phase remained alkali [54]. When sodium polymethacrylate was used, increases in the volume fraction of monomer decreased the Sauter mean drop diameter but, when a minimum value was reached, subsequent increases in the monomer fraction led to increases in drop diameter [52]. The volume fraction of monomer, at which the minimum Sauter mean drop diameter was observed, became larger as the concentration of stabilizer was increased.

As the continuous-phase viscosity increases, film drainage rate between colliding drops is expected to decrease [55]; the drop coalescence rate would also decrease. That decrease becomes more significant for smaller drop [55] which may account for a broadening of drop size distribution which was observed in the suspension polymerisation of methyl methacrylate, using sodium polymethacrylate as a suspending agent [52].

\section{Drop mixing}

In order to maintain product quality, it is sometimes important to ensure that all the polymer particles have the same chemical composition when suspension polymerization finishes. It may also be important to control polymer properties throughout the process. Achieving those aims can be difficult, especially with co-polymerization because 
monomers inside the drops usually react at different rates [56]. Therefore, in batch operation, the copolymer composition changes during the reaction. Undesirable drift in co-polymer composition may be avoided by adding one of the monomers to the reactor incrementally. That procedure will only be effective if the added monomer mixes quickly, and uniformly, with the existing drops. But, in some cases, rapid, mixing of the dispersed phases does not occur and the added monomer can remain segregated from the existing drops for a significant period of time. Any new drops, that are formed, will have a monomer composition that differs from that of the original drops. The new drops will also be unstable because the existing drops will have adsorbed most of the drop stabilizer. Adding extra drop stabilizer, to stabilize new drops, will reduce drop mixing rates further and hinder the transfer of radical generator from the "older" drops to the newer drops. Therefore, the polymerization rate is expected to be low in the new drops.

When styrene was added to an aqueous dispersion of drops that contained a solution of polystyrene in styrene, mixing of the dispersed phases was found to be slow [57]. Drop coalescence rates depended on the initial viscosity of the polystyrene solution and the drop size distribution broadened as the dispersed-phase viscosity increased. The drop mixing rate increased as the drop viscosity decreased when drop sizes exceeded a critical value. When drops were smaller than the critical size, the coalescence rate increased as the drop size increased. When two stabilised dispersions were mixed, the drop size distribution was unchanged if the initial viscosities of the monomer-polymer drops was the same in both dispersions [58]. But, the drop size distribution gradually became narrower, with the larger drops disappearing, if drops in the two stabilised dispersions initially had different compositions (and different viscosities). Drop mixing rate increased when the polymer content of all the drops increased from 0 to $5 \mathrm{wt} \%$ but further increases in polymer content lead to a reduction in mixing rate. Results from mixing experiments with styrene-polystyrene drops [58] were consistent with predictions from a model developed by Alvarez et al. (1994) [48].

A mixing problem can arise even when the concentration of radical generator is initially the same in all the monomer drops Most of the vinyl monomers that are used in suspension polymerization have a high enthalpy of polymerization (often between 30 and $90 \mathrm{~kJ} \mathrm{~mol}^{-1}$ ) and heat removal from large reactors can be difficult. Heat transfer through the reactor walls can be inadequate because large reactors have a relatively small surface/volume ratio. Heat removal rates can be increased by allowing the monomer to vaporize and then condensing the vapour outside the reactor. If new drops from the returning monomer are to be stabilized then they must obtain sufficient drop stabilizer. Also, polymerization will only occur in those new drops if they acquire some radical generator. In the suspension polymerization of vinyl chloride, monomer returning from a reflux condenser formed new drops that acquired initiator without coalescing with existing stabilized drops. In that case, the mechanism for initiator transfer through the continuous phase appeared to involve new small particles that were formed by simultaneous emulsion polymerization so that the drop size distribution became bimodal [59]. Vinyl chloride is a very reactive monomer with a high enthalpy of polymerization. Therefore, initiator is usually dispersed in the aqueous phase (and not pre-dissolved in the monomer) to avoid premature polymerization. Subsequent mixing of monomer and initiator is found to be slow and many monomer drops can remain "uninitiated" even when monomer in other drops has polymerized to a considerable extent [60], [61]. 
Transfer of initiator through the aqueous phase probably accounts for the simultaneous emulsion polymerization mentioned above. Those phenomena lead to a non-uniformity in the drops (and particles) that can affect the final polymer properties

Some desirable properties of PVC are obtained by mixing the polymer with particulate additives. Effective incorporation of those additives might be achieved by pre-mixing them with vinyl chloride before polymerization. Examination of that possibility showed that the presence of the inorganic particles influences the properties of the monomer phase and affects the drop size distribution [62].The extent of those changes depends on the particles size of the additive.

\section{Particle structure}

Polymers obtained from suspension polymerization are often recovered and processed in bulk form. But, in some cases, they are used directly as beads. Then, the internal bead structure can be important. If the beads are to be used for ion-exchange applications then the beads may need to be porous. Bead porosity can be introduced by using an inert "porogen" that is mixed with the monomer before polymerization and then removed after polymerization [63], [64]. Copolymerization of styrene (or functionalised styrene) with divinyl-benzene can provide cross-linked beads and their porosity can be controlled by using appropriate amounts of a porogen. However, the bead size distribution that is obtained from suspension polymerization is often broad; that is a disadvantage if the beads are to be used in packed columns because it leads to high pressure drops. Narrower bead size distributions can sometimes be obtained by using template particles that are made of linear polymers. Those particles, which can have a narrow size distribution, are swollen with the monomer mixture and the linear polymer is removed after polymerization [65], [66].

In the manufacture of ion-exchange resins, porosity is enhanced by the phase separation that occurs during cross-linking [67], [68], [69]. But, in vinyl chloride polymerization, phase separation is inherent because VCM and PVC are almost immiscible and polymer structure is affected by coagulation of primary polymer particles inside the drops [70]. In that case, particle porosity facilitates the subsequent uptake of plasticizers by the PVC. If monomer reflux is used to aid heat transfer from the reactor then, at low conversion, PVC porosity increases when the monomer reflux rate is high [71]. Suspension polymerization can also be used to make particles with a core-shell structure [29], [72], [73].

\section{Aqueous monomer drops}

In some commercial suspension processes, water-miscible polymers are produced in aqueous monomer drops that are dispersed in a non-aqueous continuous phase (often a hydrocarbon). If the drops are very small such a process is sometimes called "inverse emulsion polymerization" but that is a misnomer because the initiator is usually located in the aqueous drops and the polymerization mechanism is different from that found in conventional emulsion polymerization.

Although inorganic persulphates can be used as radical generators, redox initiators are sometimes preferred because they produce free radicals at relatively low temperatures. Then, at least one of the redox components is segregated from the monomer while the suspension is being formed. Otherwise, polymerization would begin prematurely. 
Aqueous reductant can be added to a dispersion of aqueous monomer drops that already contain an aqueous oxidant. Polymerization will begin when the two types of aqueous drops become mixed. Often, drops of an aqueous solution of monomer and oxidant are initially dispersed in the continuous phase which contains an oil-miscible suspending agent. Then aqueous reductant is added to start the reaction $[74,75,76]$. The two types of aqueous drops, that are initially present, must become mixed before polymerization can begin. The drop mixing rate and viscosity changes inside the monomer drops can be inter-dependent [77, 78].

In these "inverse" processes, the final particle size distributions can be wide. That might be a disadvantage for some product applications but improved control of the size distributions can be achieved by using an oscillatory baffled reactor [79].

\section{Reactor scale-up and behaviour}

When large stirred vessels are used for suspension polymerization, reactor geometry becomes important because it influences the internal liquid flow [80]. Many industrial suspension polymerizations are described as "batch" processes but, in practise, they are often semi-batch processes because some material enters the reactor after the start of polymerization. If substantial monomer reflux occurs, condensed monomer will return to the reactor continuously so that un-converted monomer is being mixed with drops of higher viscosity. Problems that may arise from that mixing are discussed above (in section 5). Other reactor types, that have also been used for suspension polymerization, include a loop reactor [81], an oscillatory baffled reactor [82] and a continuous-flow tubular reactor [83].

With suspension polymerization, reactor agitation must be good enough to promote heat transfer from the vessel and to maintain, a two-phase dispersion. Although the correlations shown in equations (2) and (3) might help in reactor scale-up, in reality, it is difficult to ensure similarity of conditions inside reactors with different sizes [1].

Successful scale-up requires the average turbulence intensity to be constant but high values for the Reynolds Number can be difficult to obtain in small reactors. In stirred vessels the Reynolds Number is given by

$R e=N D^{2} \rho_{m} / \mu$

where values for the density $\left(\rho_{m}\right)$ and viscosity $(\mu)$ are those for the whole suspension. Large values for $D^{2}$ can be obtained more easily in industrial-scale reactors than in laboratory-scale reactors [52]. With small reactors, it is not always feasible to use stirrer speeds that are high enough to compensate for the low value of $D$.

\subsection{Reactor Safety with Suspension Processes}

The potential for thermal runaway in suspension polymerization reactors cannot be ignored even though overall heat transfer from the reactor is better than that found with bulk polymerization [84]. Predictions of temperature rises, from reactor models, will only be meaningful if allowances are made for the temperature dependence of physical properties of the reactor contents [85]. The density of dispersed drops usually rises during polymerisation. That has important implications when the density of unconverted monomer is less than that of the continuous phase and when drop/particle density at partial monomer conversion exceeds that of the continuous phase. Then, sedimentation and coalescence of polymerizing drops may occur if the axial reactor mixing is not good. 
That can lead to the formation of an amalgamated mass of polymerizing material near the bottom of the reactor. Heat transfer from that agglomerate will be poor and uncontrolled temperature rises may occur within it. Subsequent increases in the vapour pressure of monomer may lead to unsafe values for the total vapour pressure in the reactor.

\subsection{Water disposal and heat recovery.}

Although the continuous phase in suspension polymerization is often regarded as chemically inert, attention must be given to its treatment. In most industrial processes the continuous phase is aqueous and it is usually purified before use. After polymerization, the water may contain residues from suspending agents, hydrolysed monomers, radical generators and any special additives that have been used. Therefore, it must be cleaned before re-use or disposal; discharge of un-treated water, to municipal drains or to rivers, is not an option. During polymerization, the continuous phase usually experiences a substantial temperature rise and heat recovery becomes important.

\section{Conclusions}

In suspension polymerization, control of drop size distribution requires clear determination of the reactor flow regime and an appropriate choice of suspending agent. Partial miscibility of some reaction components with the continuous phase and slow drop mixing can both affect the final polymer properties.

\section{Notation}

$\begin{array}{lll}a & \text { constant } & - \\ \mathrm{A}^{*} & \text { active chain centre } & - \\ \mathrm{A}^{\bullet} & \text { activating radical } & - \\ \mathrm{AM}_{\mathrm{n}}{ }^{*} & \text { growing polymer chain } & - \\ \mathrm{AM}_{\mathrm{n}}{ }^{*} & \text { growing polymer radical } & - \\ b & \text { constant } & - \\ C_{I} & \text { initiator concentration } & \mathrm{mol} \mathrm{m}^{-3} \\ C_{M} & \text { monomer concentration } & \mathrm{mol} \mathrm{m}^{-3} \\ d_{32} & \text { Sauter mean diameter } & \mathrm{m} \\ D & \text { impeller diameter } & \mathrm{m} \\ e & \text { distance between impeller blade and reactor wall } & \mathrm{m} \\ f & \text { efficiency factor } & - \\ \mathrm{I} & \text { initiator } & - \\ k_{d} & \text { initiator decomposition rate coefficient } & \mathrm{s}^{-1} \\ k_{p} & \text { propagation rate coefficient } & \mathrm{m}^{3} \mathrm{~mol}^{-1} \mathrm{~s}^{-1} \\ k_{t} & \text { chain termination rate coefficient } & \mathrm{m}^{3} \mathrm{~mol}^{-1} \mathrm{~s}^{-1} \\ \mathrm{M} & \text { monomer } & - \\ N & \text { stirrer speed } & \mathrm{s}^{-1} \\ \mathrm{R}_{\mathrm{p}} & \text { polymerization rate } & \mathrm{mol} \mathrm{m}^{-3} \mathrm{~s}^{-1} \\ R e & \text { Reynolds Number } & - \\ \mathrm{T} & \text { chain transfer agent } & - \\ \mathrm{T} & \text { radical from transfer reaction } & - \\ T a & \text { Taylor Number } & - \\ W e & \text { Weber Number } & - \\ & & \end{array}$




$\begin{array}{lll}\text { Greek letters } & \\ \mu & \text { dynamic viscosity } & \mathrm{Pa} \mathrm{S} \\ v_{c} & \text { kinematic viscosity } & \mathrm{m}^{2} \mathrm{~s}^{-1} \\ \rho_{m} & \text { density } & \mathrm{kg} \mathrm{m}^{-3} \\ \sigma & \text { interfacial tension } & \mathrm{N} \mathrm{m}^{-1} \\ \phi & \text { dispersed phase volume fraction } & - \\ \text { References } & & \end{array}$

[1] H. G. Yuan, G. Kalfas, W. H. Ray, Rev. Makromol. Chem. Phys. 1991, C31 (2/3), 215-299.

[2] E. Vivaldo-Lima, P. E. Wood, A. E. Hamielec, Ind. Eng. Chem. Rev. 1997, 36, 939965.

[3] R. Ashady, Colloid Polym. Sci. 1992, 270, 717-732.

[4] B. W. Brooks, Makromol. Chem. Makromol. Symp. 1990, 35/36, 121 - 140.

[5] C.H. Bamford, W.G. Barb, A.D. Jenkins, P.F. Onyons, The Kinetics of Vinyl Polymerisation by Radical Mechanisms, Butterworth, London, 1958.

[6] B. W. Brooks, Proc. Roy. Soc. Lond. 1977, A 357, 183 - 192.

[7] J. T. S. Bogunjoko, B. W. Brooks, Makromol. Chem. 1983, 184, 1603 - 1621.

[8] N. Tefera, G. Weickert, Makromol. Chem. Phys. 1994,195, 3067 - 3085.

[9] J. H. Duerksen, A. E. Hamielec and J. W. Hodgins, A.I.Ch.E.J. 1967, 13, 1081.

[10] M. J. Rosen, Surfactants and Interfacial Phenomena, 2nd. Edition, Wiley, New York, 1989.

[11] R. P. Borwanker, S. I. Chung, D. T. Wasan, J. Appl. Polym. Sci. 1986, 32, 5749 5762.

[12] M. Zerfa, B.W. Brooks, Colloids and Surfaces A, Phys. Eng. Aspects, 1998, 132, $267-273$.

[13] L. I. Atanase, G. Riess, Colloids and Surfaces A: Physicochem. Eng. Aspects, 2010, 355, 29-36.

[14] M. Zerfa, B.W. Brooks, Chem. Eng. Sci. 1996, 51, 3591 - 3611.

[15] S. Ormondroyd, Br. Polym. J, 1988, 20, 353 - 359.

[16] M. D. Horrill, B. W. Brooks, Instn Chem. Engrs Research Event, Leeds, 1996, 545 547.

[17] Y. Z. Bao, B. W. Brooks, J. Appl. Polym. Sci. 2002, 85, 1544 -1552.

[18] F. Lerner, S. Nemet, Plastics, Rubber and Composites, 1999, 28 (3), 100-104.

[19] J.A. Davidson, D.E. Witenhafer, J. Appl. Polym. Sci., Polym. Phys. Ed. 1980, 18, 5169. 
[20] S. Georgiadou, B. W Brooks, Chem. Eng. Sci, 2005, 60, 7137-7152.

[21] S. Georgiadou, B.W. Brooks, Chem. Eng. Sci, 2006, 61, 6892-6901.

[22] S. X. Zhou, Z. X. Weng, Z. M. Huang, Z. R. Pan, J. Appl. Polym. Sci., 2001, 79, $1431-1438$.

[23] S. U. Pickering, J. Chem. Soc., 1907, 91, 2001-2021.

[24] M. Munzer, E. Trommsdorff, in Polymerization Processes (Eds: C. E. Schildknecht, I. Skeist), Chapter 5, 106, Wiley. New York, 1977.

[25] Z. Wang, B. W. Brooks, Polymer International, 1992, 28, 239 - 211.

[26] D. Wolters, W. Meyer-Zaika, F. Bandermann, Macromol. Mater. Eng. 2001, 286, 94-106.

[27] E. O’Shima, M. Tanaka, Kagaku Kogaku Ronbunshu, 1982, 8, 188.

[28] Z. Wang, B. W. Brooks, Polymer International, 1993, 30, 317 - 326.

[29] Q. Gao, C. Wang, H. Liu, C. Wang, X. Liu, Z. Tong, Polymer, 2009, 50, 2587-2594.

[30] S. Tarimala, L. L. Dai, Langmui,r 2004, 20, 3492-3494.

[31] B. P. Binks, S. O. Lumsdon, Langmuir, 2001, 17 (15), 4540 -4547.

[32] K. Golemanov, S. Tcholakova, P. A. Kralchevsky, K. P. Ananthapadmanabhan, A. Lips, Langmuir, 2006, 22 (11), 4968-4977.

[33] M. A. Malik, R, Mukhtar, S.A.R. Zaidi, S. Ahmed, M. A. Awan, Reactive \& Functional Polymers, 2002, 51, 117-120.

[34 R. Ashady, G. W. Kenner, A. Ledwith, J. Polym. Sci., Polym. Chem. Edit. 1974, 12, $2017-2025$.

[35] Z. Izumi, H. Kitagawa, J. Polym. Sci. A-1, 1967, 5, 1967 - 1975.

[36] M. Langsam, J. T. Cheng, J. Appl. Polym. Sci. 1985, 30, 1285 -1308.

[37] C. G. Hagberg, Polym. Mater. Sci. Eng. 1988, 58, 614 - 621.

[38] B. W. Brooks, in Handbook of Polymer Reaction Engineering (Eds: T. Meyer, J. Keurentjes), Chapter 5, Vol 1, pp 213-247, Wiley-VCH, Weinheim, 2005.

[39] R. Shinnar, J. M. Church, Ind. Engng. Chem. 1960, 52, 253-256.

[40] C. Y. Wang, R. V. Calabrese, A.I.Ch.E.J. 1986, 32, 667 - 676.

[41] F. Jahanzad, S. Sajjadi, B. W. Brooks, Macromolecular Symposia, 2004, 206, 255 262.

[42] M.F. Cunningham, Polym. React. Eng. 1999, 7 (2), 231.

[43] F. Jahanzad, S. Sajjadi, B. W. Brooks, Chem. Eng. Sci. 2005, 60, 5574 - 5589.

[44] M. Konno, K. Arai, S. Saito, J. Chem. Eng. Japan, 1982, 15, 131 - 135.

[45] F. B. Sprow, A.I.Ch.E.J. 1967, 13, 954 - 998.

[46] W. J. Howarth, Chem. Eng. Sci. 1964, 19, 33 - 38. 
[47] R. Shinnar, J. M. Church, Ind. Engng. Chem. 1960, 52, 253 - 256.

[48] J. Alvarez, J. J. Alvarez, M. A. Hernandez, Chem. Eng. Sci. 1994, 49, 99 - 113.

[49] G.I. Taylor, Proceedings of the Royal Society A, 1932, 138, 41-48.

[50] G.I. Taylor, Proceedings of the Royal Society A, 1934, 146, 501-523.

[51] C. Jegat, A. Bois, M. Camps, Journal of Polymer Science, 2001, 39, 201-210.

[52] S. Georgiadou, B. W Brooks, Chem. Eng. Sci. 2005, 60, 7137-7152.

[53] S. Georgiadou, B.W. Brooks, Chem. Eng. Sci. 2006, 61, 6892-6901.

[54] S. Georgiadou, B. W Brooks, Polymer International, 2006, 50, 525-534.

[55] S. Kumar, R. Kumar, K.S. Gandhi, Chem. Eng. Sci. 1993, 48 (11), 2025-2038.

[56] F. W. Billmeyer, Textbook of Polymer, Science, Wiley, New York, 1971.

[57] S. Hashim, B.W. Brooks, Chem. Eng. Sci. 2002. 57, 3703-3714.

[58] S. Hashim, B.W. Brooks, Chem. Eng. Sci. 2004, 59, 2321-2331.

[59] M. Zerfa, B. W. Brooks, Chem. Engng. Sci., 1997, 52, 2421-2427.

[60] M. Zerfa, B. W. Brooks, J. Appl. Polym. Sci. 1996, 60, 2077-2086.

[61] M. Zerfa, B. W. Brooks, J. Appl. Polym. Sci. 1997, 65, 127-134.

[62] S. Georgiadou, N. L. Thomas, M. Gilbert1 and B. W. Brooks, Plastics, Rubber and Composites, 2008. 37 (9/10), 431-435.

[63] F.S. Macintyre, D.C. Sherrington, Macromolecules, 2004, 37 (20), 7628-7636.

[64] Q. C. Wang, K. Hosoya, F. Svec, J. M. J. Frechet, Anal. Chem. 1992, 64 (11), 1232 1238 .

[65] L. Ye, K. Mosbach, Proc. of Mat. Res. Soc. Symp. 2002, 723, M3.1.1 - M3.1.9.

[66] K. Lewandowski, F. Svec, J. M. J. Frechet, J. Appl. Polym. Sci. 1998, 67, 597-607.

[67] O. Okay, E. Soner, A. Güngör, T. I. Balkas, J. Appl. Polym. Sci. 1985, 30, 2065 2074.

[68] Y. Ohtsuka, H. Kagaguchi, T. Hamasaki, J. Appl. Polym. Sci., 1982, 27, 1771 1782.

[69] W. Kangwansupamonkon, S. Damronglerd, S, Kiatkamjornwong, J. Appl. Polym. Sci., 2002, 85, 654 - 669.

[70] J. A. Davidson, D. E. Witenhafer, J. Polym. Sci: Polymer Physics Edition, 1980, 18 (1), $51-69$.

[71] M. Zerfa, B.W. Brooks, Chem. Eng. Sci. 1997, 52, 2421-2427.

[72] J. Hu, Z. Zheng, F. Wang, W. Tu, L. Lin, Pigment \& Resin Technology, 2009, $\underline{38}$ (5), $280-284$.

[73] M. Jonsson, O. Nordin, E. Malmström, C. Hammer, Polymer, 2006, 47 (10), 3315 3324. 
[74] Z. Liu, B. W. Brooks, J. Appl. Polym. Sci., 1997, 66, 2191-2197.

[75] Z. Liu, B. W. Brooks, J. Polym. Sci., 1999, A37, 313-324.

[76] M. V. Dimonie, N. N. Marinescu, D. S. Vasilescu, O. Shaffer, H. Caldararu, A. Caragheorgheopol, J. J. Languri, Macromol. Sci., 1992, A29, 277.

[77] Z. Liu, B. W. Brooks, Polymer, 1999, 40, 2181-2188.

[78] Z. Liu, B. W. Brooks, J. Polym. Sci., 1997, 66, 2191-2197.

[79] X. Ni, J. C. Johnstone, K. C. Symes, B. D. Grey, D. C. Bennett, A.I.Ch.E.J., 2001, $47,1746-1757$.

[80] J. Y. Oldshue, D. O. Mechler, D. W., Grinnell, Chem. Eng. Prog. 1982, 198, 68-74.

[81] M. Tanaka, T. Takahashi, I. Kimura, Chem. Eng. Tech. 1996, 19, 97-102.

[82] X. Ni, Y. Zhang, I. Mustafa, Chem. Eng. Sci. 1999, 54, 841-850.

[83] P.J. Dowding, J.W. Goodwin, B. Vincent, Colloid Polym Sci. 2000, 278, 346-351.

[84] S. Nemeth, F. Thyrion, Chem. Eng. Technol. 1995, 18, 315-323.

[85] B. W. Brooks, J. Appl. Polym. Sci. 1983, 28, 619-623. 